University for Business and Technology in Kosovo

UBT Knowledge Center

Nov 7th, 4:45 PM - 5:00 PM

\title{
The use of Intelligent System in transport and concrete benefits when using this system in context of saving fuel
}

Muhamet Avdyli

Universiteti Ukshin Hoti, m_avdyli@hotmail.com

Follow this and additional works at: https://knowledgecenter.ubt-uni.net/conference

Part of the Computer Sciences Commons

\section{Recommended Citation}

Avdyli, Muhamet, "The use of Intelligent System in transport and concrete benefits when using this system in context of saving fuel" (2014). UBT International Conference. 62.

https://knowledgecenter.ubt-uni.net/conference/2014/all-events/62

This Event is brought to you for free and open access by the Publication and Journals at UBT Knowledge Center. It has been accepted for inclusion in UBT International Conference by an authorized administrator of UBT Knowledge Center. For more information, please contact knowledge.center@ubt-uni.net. 


\title{
The use of Intelligent System in transport and concrete benefits when using this system in context of saving fuel
}

\author{
Muhamet Avdyli \\ Universiteti „Ukshin Hoti“, Republika e Kosovës \\ m_avdyli@hotmail.com
}

\begin{abstract}
Abstrakt. The intelligent systems in transport are being used increasingly in order to facilitate the transportation management, improving the economic aspect as well as increasing safety during the transportation process. The article initially makes an analysis of the evolution, distribution and use of the telematics systems in the transportation business until nowadays, extracting as a result some suggestions. Furthermore, the article analysis the economic character and drawing the concrete results, that supports the use of such systems and makes them a must in progress of a transport business. The direct impact in terms of economics has the managerial aspect too, which is also part of the article. The analysis was done with the data of telematics system installed in a business NTSH Nderimi - Ferizaj, Republic of Kosovo.
\end{abstract}

Keywords: ITS, GPS, vehicle, tracking, fuel, telematics, technologhy, menagement

\section{Introduction}

\subsection{Use of telematic system in the transport}

The telematik system in transportation has to do with the sending, receiving and reservation of information through the telecomunication and devices as well as controll of the objects in distance. The Global Position System is the main technologie that is included in the system discussed on this article and that can be called differently vehicle telematics.

The use of telematics on road transportation realizes an intelligent combination between a control center and intelligent devices in vehicle which are required to develop secure communication, free and ecologicall clean.

The telematics system in vehicle can be used in several aspects such as: gathering information about the movement, menagement of processes during movement, tracking of vehicle location, the finding of stolen vehicles, offering services connected with the information for the driver, the direction of the vehicle movement, the spented road etc.

\subsection{Interest or economic effects of businesses that impletment intelligent systems of transportation.}

Starting from a study conducted in a USA company which has shown interest in studying the effects that give the use or implementation of intelligent systems on transportation enterprises has determined that has growth interest for the systematic collection of data about these effects but they are still in the mix or too low level. And for this purpose every study done in this direction enrich this area of study. In the world there are not many sudies done of this kind and one has been done in the USA where right after instaling the intellegent transportation system in a company the analyses of the benefit or profitability is a result of using these systems.

The effectiveness of this technologhy and the process of software development have been done for the NOVA Groupe company which has a transport diversitty withing an hour (orders were given to the drivers while they were driving).

Datas were collected for the 2008 quarterly period before the use of Dispatch Tools software and the 2009 quarterly period after the use of respective software. For this analysis have been taken into consideration only dispatching personnel and drivers that have effected those two categories of people (employees).

From this measurement or comparison has come to conclusion that productivity of the company after applying this type of software or application has increased for $24 \%$ except the side effects such as 
reduction of dispatchers stress and the easier communication with the dispatchers of the various offices of the company considering the requirements for diverse reports that those offices require.

Also there were a results studied in relation to the use of "Fleet Services" system in the Schöni Transport AG company, cooperation with insurance company Allianz Suisse. This company will equip a part of its fleet of the vehicles with the intelligent telematics system.

The heart of this telematik system is called "On Board Unit", which will be mounted in the vehicle and will transmit the important information about the vehicle. It is confirmed that the system "Fleet Services" concretely provides the following advantages:

1. Increase efficiency: Through optimization of the use of vehicles, the "Fleet Services" system reduces the residence time of the vehicle (during which time the vehicles are not moving) and contributes to a better control of the delivery of goods and the time during which vehicles are moving.

2. Does the cost reduction of the vehicle: as a result of transparency, fuel costs, the maintenance costs and reduce the unauthorized trips.

4. Provides more security for the driver and vehicle: automatic or manual otification in case of accidents, emergencies or defects performed directly by vehicle.

5. Protection from theft: locating the whereabouts of vehicle will increase the security for the company and the customer.

6. Data records in case of an accident: by analyzing these data can be rebuilt a causes of the accident, making it possible to thus rejecting the unjust claims of demands by the parties.

\subsection{Benefits of using the vehicle tracking system}

From the angle of current users can be said that are multiple benefits when using this system. The first that have been proven about this system is that investment can be returned to the company very quickly, especially if the fleet has a large number of the vehicles, because logically on such auto parks misuse is greater.

Very quickly the savings or positive effects will be observed in reduction of fuel costs for the spented kilometers. It is shown that the money that were spent or allocated for fuel have been decreased on an average in the amount of $20-40 \%$ and in some cases even up to $50 \%$.

Reducing the vehicle kilometers passed directly as a result of expenses that relate to maintenance of vehicles that are not low (amortization, the regular services, the spare parts, etc.). When the unreasonable per diem payment is added into this then is even more clear what extend decreased costs or how much we save.

So here we are dealing whith time planning, organizing efficient of transportation, seeing where the vehicles are in certain moments, we can also give recommendation about the upcoming destinations etc.

\section{Study done in N.T.SH Nderimi - Ferizaj, Republic of Kosova}

To see much better saving effects or application results of a vehicle tracking system in the distance we are considering two heavy trasport vehicles which belongs to the transportation company N.T.SH. Nderimi from Ferizaj.

For resourch have been used a period of a month (1 Apr - $30 \mathrm{Apr}$ ) in 2012 year when these vehicles didn't have application instaled for the remote monitoring from the distance and on the same period of time (1 Apr - $30 \mathrm{Apr})$ in 2013 year when these vehicles were managed through the application mentioned. The April was chosen because during this month the vehicles spend more miles of road. The results obtained from these two periods are presentd in the following tables. 
Table 1. Results obtained before the instalation of device for monitoring.

\begin{tabular}{|c|c|c|c|c|}
\hline Vehicle & $\begin{array}{c}\text { Spent } \\
\text { road } \\
/ \mathrm{Km}\end{array}$ & $\begin{array}{c}\text { The spended } \\
\text { level of fuel/L }\end{array}$ & $\begin{array}{c}\text { The spended } \\
\text { fuel in } \\
100 \mathrm{~km} / \mathrm{L}\end{array}$ & $\begin{array}{c}\text { The period of } \\
\text { time }\end{array}$ \\
\hline $\mathbf{0 5 - 1 5 6 - A T}$ & $\mathbf{3 2 1 4 , 6}$ & $\mathbf{1 6 1 0 , 1 4}$ & $\mathbf{5 0 , 1}$ & $\mathbf{( 0 1 . 0 4 - 3 0 . 0 4 ) 2 0 1 3}$ \\
\hline $\mathbf{0 5 - 8 1 8 - A D}$ & $\mathbf{2 8 9 7 . 4}$ & $\mathbf{1 4 2 5 , 5 2}$ & $\mathbf{4 9 , 2}$ & $\mathbf{( 0 1 . 0 4 - 3 0 . 0 4 ) 2 0 1 3}$ \\
\hline
\end{tabular}

Table 2. Results after the installation of telematics system for monitoring.

\begin{tabular}{|c|c|c|c|c|}
\cline { 2 - 3 } Vehicle & $\begin{array}{c}\text { Spent } \\
\text { road } \\
/ \mathrm{Km}\end{array}$ & $\begin{array}{c}\text { The spended } \\
\text { level of fuel } / \mathrm{L}\end{array}$ & $\begin{array}{c}\text { The spended } \\
\text { fuel in } \\
100 \mathrm{~km} / \mathrm{L}\end{array}$ & The period of time \\
\hline $\mathbf{0 5 - 1 5 6 - A T}$ & $\mathbf{4 7 9 5 , 7 0}$ & $\mathbf{2 0 2 0 , 9 0}$ & $\mathbf{4 2 . 1 4}$ & $\mathbf{( 0 1 . 0 4 - 3 0 . 0 4 ) 2 0 1 3}$ \\
\hline $\mathbf{0 5 - 8 1 8 - A D}$ & $\mathbf{3 4 8 2 , 9 0}$ & $\mathbf{1 2 9 5 , 6 3}$ & $\mathbf{3 7 . 1 2}$ & $\mathbf{( 0 1 . 0 4 - 3 0 . 0 4 ) 2 0 1 3}$ \\
\hline
\end{tabular}

The results set out in Table 1 are generated manually by the respective company employee, while the results set out in Table 2 are obtained from the application report as you can see on the following figures for these two vehicles.

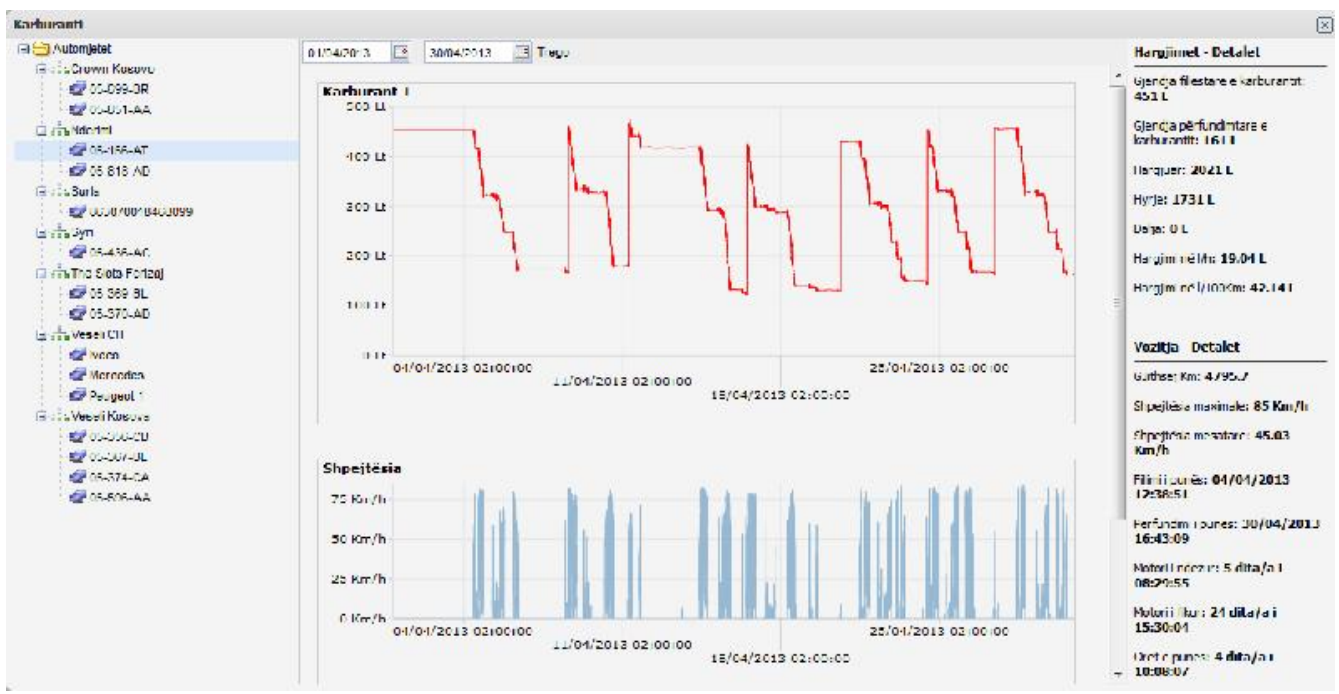

Fig. 1. Vehicle 05-156-AT 


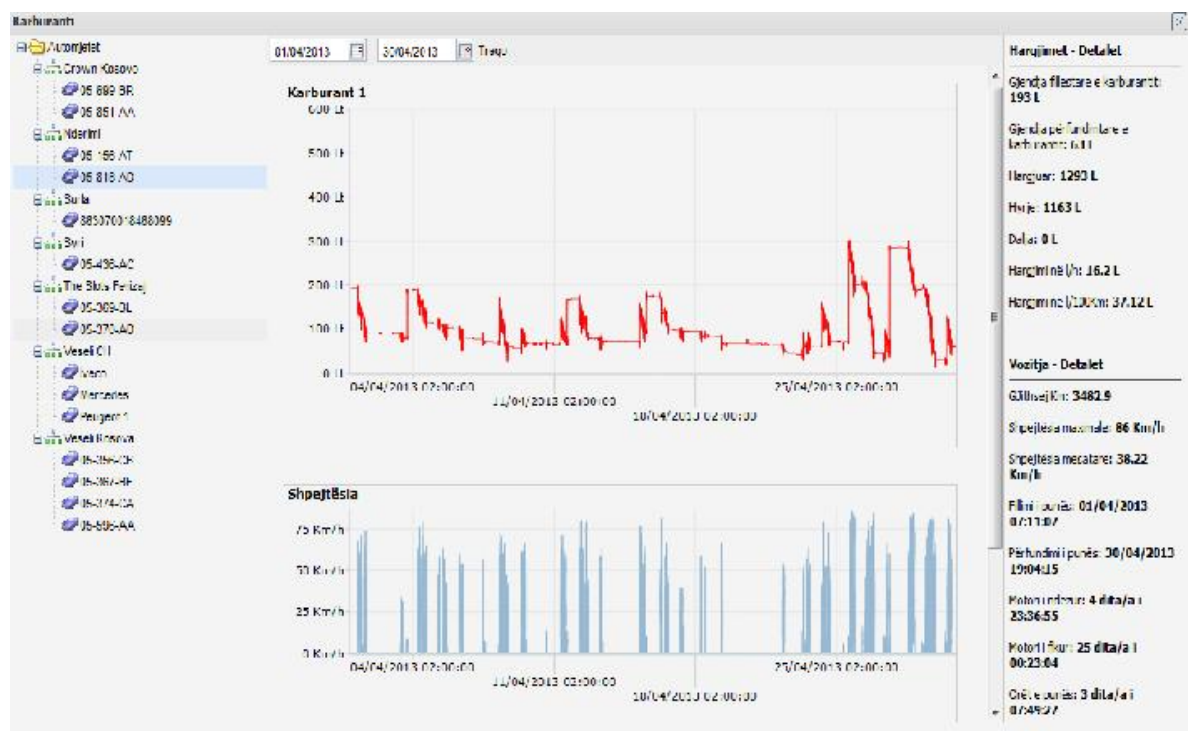

Fig. 2. Vehicle 05-818-AD

By comparing these results we can draw the conclusion that first vehicle during the period of time without a monitoring device installed, in $100 \mathrm{~km}$ of road has spent more than 7.96 liters more than on the second time. While the second vehicle for the same period of time has spent 12.08 liters more than on the second time.

On the following graph you can clearly see the savings realized for the first and the second vehicle

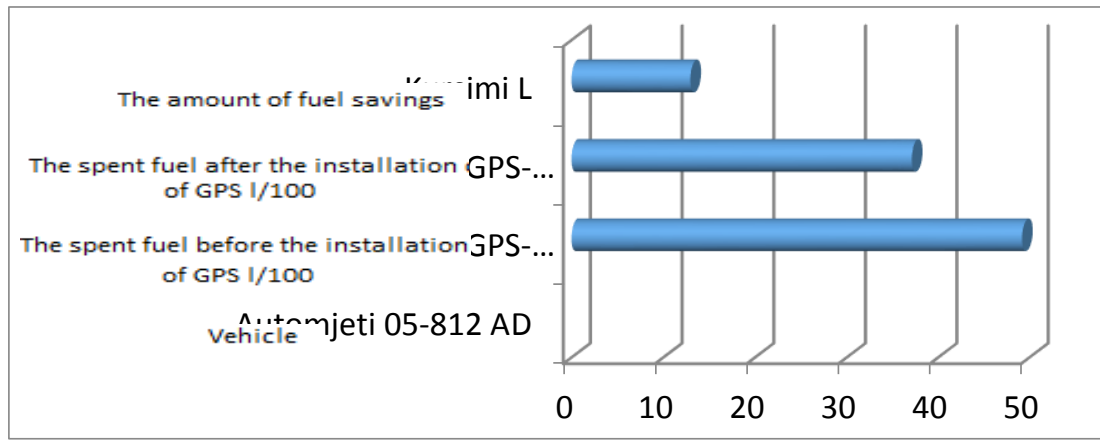

Fig. 3. Graph of fuel savings for the first vehicle

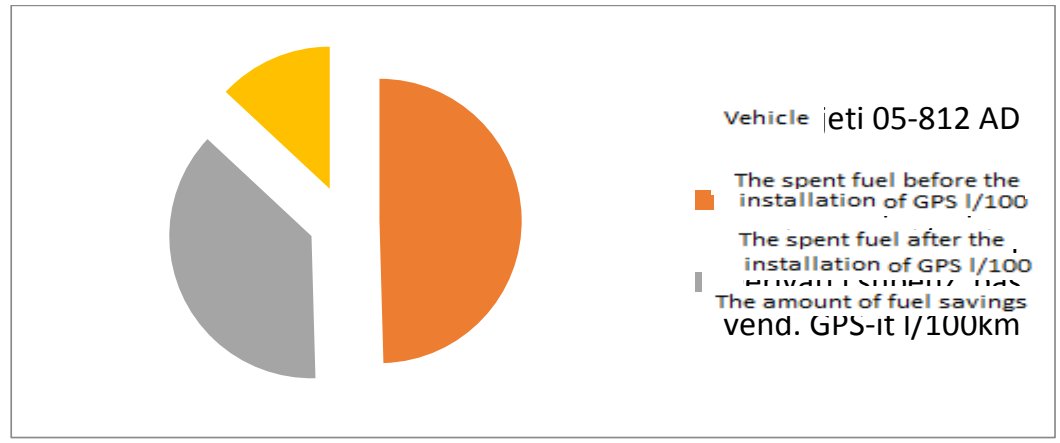

Fig. 4. Graph of fuel savings for the second vehicle

A noticeable element to automatic report is generated through application is that neither one of vehicles have not exceeded the maximum speed to $86 \mathrm{~km} / \mathrm{h}$, which suggests that optimal driving has greatly 
conditioned the derivative costs be smaller.The possibility that application offers as proof of long stops when the engine of the vehicle is on and many other components have a big savings effect.If we consider a total of 30 transportation vehicles that would of have done $500000 \mathrm{~km}$ of road, it appears that the application of such a system for fleet management not only that pays off fast but also brings multiple economic benefits directly related to lowering costs and efficient management.

If is analyzed and calculated that on average in the spent $100 \mathrm{~km}$ of road are saved $10.07(12.08+8.06$ $=20.14 / 2$ ) liters of fuel and if this account is for a vehicle which has passed 500,000 km would save approximately 50,350 liters of fuel per vehicle. If this estimate will be made for 30 vehicles then figures arises much bigger. As a final conclusion obtained from this study done for these two vehicles it appears that the average fuel savings is $20.13 \%$, which is obtained from the expression.

$15.90 \%$, savings for the first vehicle after the ITS placed.

$24.36 \%$, savings for the second vehicle after the ITS placed.

$15.90 \%+24.36 \%=40.26 \%$

\section{The Algorithm Used}

Algorithm used on the pic 5, makes it possible to find the fuel level at any point of his movement, which makes it possible to find the points where there are marked fuel differences. To distinguish the inputs and output of fuel in the tank, you need difference between two consecutive points on the graph, which should be greater than the parameter inputs and minimal fuel outputs in the tank, since only on this case they are considered as input or output.

The algorithm also determines the speed of movement of the vehicle and to record the input and output of fuel, a condition should be met that the speed should be zero, since only in this case we can output or entry fuel (vehicle must be stop for input or output of fuel).

This condition will allow us not to consider output and input level changes of fuel levels while traveling with the vehicle (downhill and/or vice versa).

The fuel levels are calculated through the formula: initial status + inputs - the final status - outputs. Block scheme or logical algorithm regarding fuel, based on which is written the program will look as below:

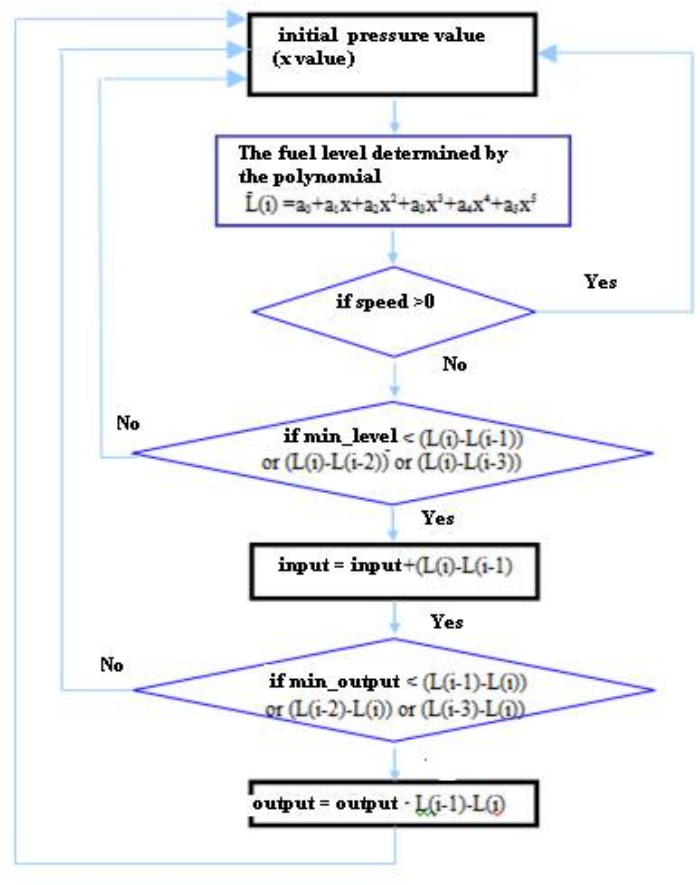

Fig. 5. The algorithm for calculating costs of metered fuel in vehicle 


\section{Conclusion}

The purpose of the study is that through the basic structure and function of telematics system to analyze the possibility of their use in transport and shown about the effects of its use. Implementation of telematics in the transport system has great significance in ensuring overall mobility enabling modern business that will satisfy market competition.

Telematics systems more developed and that offers various opportunities, impact directly on the transport process offering opportunities for successful management.

The proper use of these systems may lead in a significant increase in efficiency and productivity of the work on the various car parks, reducing transportation costs, lowering the cost of the vehicle and exactly what is shown by a study specified, which has to do with reduce of fuel costs for the vehicle, safety and environmental spatial. Using telematics system of transportation will not solve all problems that arise during this process, but shows in the other problems that need attention and care that the same be fixed or eliminated.

In the future we can expect that these systems are more prevalent with the aim of increasing efficiency in taking care of the environment and preventing pollution of gases harmful to the environment, except the obvious savings in fuel. The use of telematics systems enable vehicles to move with greater efficiency having in mind the cost of fuel.

By studying these circumstances can be concluded that fuel cost savings over the use of these systems can go up to $20 \%$.

\section{References}

1 Milan Maksic "Mogucnosti koriscenja telematskih sistema u transport"

2 Telematika v automobile. A. Stern, T Cepin, J Bester, Labaratorija za telekomunikacije, Fakultet za Elektrotehniku, Univerzitet v Ljubljana, "Intelligent transport systems in commercial fleet management: a study of short term economic benefits

3 Kenneth Button, Elly Doyle \& Roger Stough page 155-170”, Aplication from Company N.T.SH “ Triola Group" Ferizaj-Kosova 